\title{
Polymorphism of waxy proteins in Spanish hulled wheats
}

\author{
C. Guzmán ${ }^{1 *}$, L. Caballero ${ }^{2}$, M. V. Gutierrez ${ }^{1}$ and J. B. Alvarez ${ }^{1}$ \\ ${ }^{1}$ Departamento de Genética, Escuela Técnica Superior de Ingenieros Agrónomos y de \\ Montes, Edificio Gregor Mendel, Campus de Rabanales, Universidad de Córdoba, \\ ES-14071 Córdoba, Spain and ${ }^{2}$ Departamento de Mejora Genética Vegetal, Instituto de \\ Agricultura Sostenible, Consejo Superior de Investigaciones Científicas, Apdo. 4084, \\ ES-14080 Córdoba, Spain
}

\begin{abstract}
Hulled wheats are neglected crops that have potential in plant breeding programmes of modern durum and common wheat. Among these wheats, three species were widely cultivated in Spain until the mid 20th century: Triticum monococcum ssp. monococcum (einkorn), Triticum turgidum ssp. dicoccum (emmer) and Triticum aestivum ssp. spelta (spelt). One important aspect of wheat grain quality is starch composition, which is related to the action of waxy proteins. A collection of 536 accessions of Spanish hulled wheats was analyzed for waxy protein composition using sodium dodecyl sulphate-polyacrylamide gel electrophoresis (SDS-PAGE). Polymorphism was found for the Wx-A1, Wx-B1 and Wx-D1 proteins, including new and null alleles in the three species. An allelic variant with an electrophoretic mobility not previously described was found in einkorn wheat. In emmer and spelt, some alleles with different mobility were also found. A $W x-B 1$ null allele was detected in emmer wheat, and null alleles for $W x-A 1, W x-B 1$ and $W x-D 1$ were found in spelt wheat. The variations found could be used to enlarge the gene pool available to breeders, and to design new cultivars with different levels of amylose content.
\end{abstract}

Keywords: amylose content; genetic polymorphism; hulled wheats; waxy proteins

\section{Introduction}

Hulled wheats are the wild or cultivated species of the Triticum genus, which have glumes that tightly enclose the grains, even after normal threshing. In Spain, three species of hulled wheats were widely cultivated until the late 1960 s: Triticum monococcum L. ssp. monococcum $(2 n=2 x=14, \mathrm{AA})$, T. turgidum ssp. dicoccum Schrank em. Thell. $(2 n=4 x=28, \mathrm{AABB})$ and $T$. aestivum ssp. spelta L. em. Thell. ( $2 n=6 x=42$, AABBDD). Nowadays, only emmer and spelt wheat are still cultivated, and solely in marginal farming areas of Asturias (North of Spain). Fortunately, some of the biodiversity that once

*Corresponding author. E-mail: ge2gugac@uco.es existed is conserved in germplasm banks. Due to the growing interest in natural food, some of these ancient crops are undergoing a revival in European agriculture. In the last decade, our research group has investigated three important collections of Spanish hulled wheats, mainly for genetic variation in seed storage proteins (Caballero et al., 2001, 2004a, b; Pflüger et al., 2001; Alvarez et al., 2006). The high variability detected in these species suggests that these collections are useful gene reservoirs that can be used in breeding programmes.

The starch composition of wheat grain has a primary influence on flour quality. Wheat starch consists of two types of glucose polymers, the essentially linear amylose and the highly branched amylopectin, in a ratio of 22-35:68-75\%. Synthesis of amylose in the seed endosperm is carried out by the waxy proteins or granule-bound starch synthases that are encoded by genes 
located in the $W x$ locus on the homoeologous group 7 chromosomes (Ainsworth et al., 1993). In common wheat, the $W x-A 1$ locus is located on chromosome 7AS, the $W x-B 1$ locus on $4 \mathrm{AL}$ (a segment of chromosome 7BS that has been translocated) and the $W x-D 1$ locus on chromosome 7DS. Since starch properties such as gelatinization, pasting and gelation depend on the amylose: amylopectin ratio (Zeng et al., 1997), these proteins are very important in terms of flour quality.

The aim of this study was to assess waxy protein polymorphism in a broad collection of Spanish hulled wheats.

\section{Material and methods}

\section{Plant material}

In the current study, 536 Spanish hulled wheat lines (29 lines of einkorn, 87 lines of emmer and 420 lines of spelt) were analyzed. These lines were derived by single seed selection from an equal number of accessions obtained from the National Small Grain Collection (Aberdeen, MD, USA), the Center for Genetic Resources (The Netherlands) and the Centro de Recursos Fitogenéticos-INIA (Alcalá de Henares, Spain). The plants were grown under field conditions during 2008, and several spikes per plant were protected to prevent random crossings. Durum wheat cultivars (cvs). Langdon and Mexicali and common wheat cultivar (cv). Chinese Spring were used as standards.

\section{Starch extraction and electrophoretic analysis}

Twenty milligrams of flour were mixed with $1 \mathrm{ml}$ of distilled water and incubated at $4^{\circ} \mathrm{C}$ for $24 \mathrm{~h}$. The homogenate was filtered through Miracloth and centrifuged at $14,000 \mathrm{~g}$ for $1.5 \mathrm{~min}$. The pellet was washed with $1 \mathrm{ml}$ of buffer A $(55 \mathrm{mM}$ Tris-HCl, pH 6.8, 2.3\% (w/v) SDS, 2\% $(\mathrm{w} / \mathrm{v})$ dithiothreitol (DTT) and 10\% (v/v) glycerol), according to the method of Echt and Schwartz (1981). Then, $1 \mathrm{ml}$ of buffer A was added to the pellet and left for $30 \mathrm{~min}$ at room temperature. The pellet was washed three times with distilled water, once with acetone and then air-dried. The residue was mixed with $80 \mu \mathrm{l}$ of buffer A, heated in a boiling water bath for $2 \mathrm{~min}$, cooled on ice and centrifuged.

Aliquots of supernatant $(20 \mu \mathrm{l})$ were loaded in vertical SDS-PAGE slabs in a discontinuous Tris-HCl-SDS buffer system ( $\mathrm{pH}: 6.8 / 8.8$ ) at a polyacrylamide concentration of $12 \%(\mathrm{w} / \mathrm{v}$, cross-linker (C): $0.44 \%)$. The Tris- $\mathrm{HCl} /$ glycine buffer system of Laemmli (1970) was used. Electrophoresis was performed at a constant current of
$30 \mathrm{~mA} / \mathrm{gel}$ at $18^{\circ} \mathrm{C}$, continuing for $4 \mathrm{~h}$ after the tracking dye migrated off the gel. Protein bands were visualized by silver staining.

For two-dimensional PAGE (2D-PAGE), $8.0 \mathrm{mg}$ of starch was soaked at room temperature in $300 \mu$ l of lysis buffer (8 M urea, 2\% ampholine pH 3.5-10 (Pharmacia) and 5\% DTT). After centrifugation, the supernatant containing the solubilized proteins was subjected to 2D-PAGE using isoelectric focusing (IEF) for the first dimension and SDS-PAGE for the second. IEF gels contained 2.5\% (v/v) ampholines ( $\mathrm{pH} 3-10 / 5-8$ and 8-10, $1: 1)$. Focusing commenced from the acidic end $(0.01 \mathrm{M}$ $\mathrm{H}_{3} \mathrm{PO}_{4}$ ) at $200 \mathrm{~V}$ for $30 \mathrm{~min}$, and continued at $400 \mathrm{~V}$ for $17 \mathrm{~h}$, and then at $800 \mathrm{~V}$ for $1 \mathrm{~h}$ at room temperature. After IEF, SDS-PAGE was conducted as described above.

\section{Results and discussion}

The studies carried out on waxy proteins polymorphism have shown that variability is relatively low compared with other cereal grain proteins, such as seed storage proteins. However, Yamamori et al. (1994, 1995) found five alleles for the $W x-A 1$ gene in common wheat, and another six alleles have been described for the $W x$-B1 gene in common and durum wheats (Rodríguez-Quijano et al., 1998). More recently, Caballero et al. (2008) reported high variability for these proteins in some ancient wheats and related species.

Ten waxy alleles (two for $W x-A^{m} 1$ locus, two for $W x-A 1$, three for $W x-B 1$ and three for $W x-D 1)$ were detected in the lines herein evaluated (Table 1). In all cases, one of these alleles was clearly predominant, while the others were rare or very rare. For the $W x-A^{m} 1$ locus, the allele $W x-A^{m} 1 a^{\prime}$ that exhibited lower mobility than the $W x-A^{m} 1 a$ was only found in a single accession (BGE-014269). Both alleles showed higher mobility than that of the $W x-A 1 a$ allele detected in polyploid wheat

Table 1. Variability and allelic frequencies (in brackets) detected for waxy genes in the three collections evaluated

\begin{tabular}{lllll}
\hline Locus & Alleles & $\begin{array}{l}\text { Einkorn } \\
(n=29)\end{array}$ & $\begin{array}{l}\text { Emmer } \\
(n=87)\end{array}$ & $\begin{array}{l}\text { Spelt } \\
(n=420)\end{array}$ \\
\hline$W x-A^{m} 1$ & $\mathrm{a}$ & $28(96.6)$ & - & - \\
& $\mathrm{a}^{\prime}$ & $1(3.4)$ & - & - \\
$W x-A 1$ & $\mathrm{a}$ & - & $87(100)$ & $384(91.4)$ \\
& $\mathrm{b}$ & - & 0 & $36(8.6)$ \\
$W x-B 1$ & $\mathrm{a}$ & - & $85(97.8)$ & $317(75.5)$ \\
& $\mathrm{b}$ & - & $1(1.1)$ & $49(11.7)$ \\
$W x-D 1$ & $\mathrm{c}^{\prime}$ & - & $1(1.1)$ & $54(12.8)$ \\
& $\mathrm{a}$ & - & - & $418(99.6)$ \\
$H_{\mathrm{e}}$ & $\mathrm{b}$ & - & - & $1(0.2)$ \\
& $\mathrm{g}$ & - & - & $1(0.2)$ \\
& & 0.067 & 0.023 & 0.189 \\
\hline
\end{tabular}




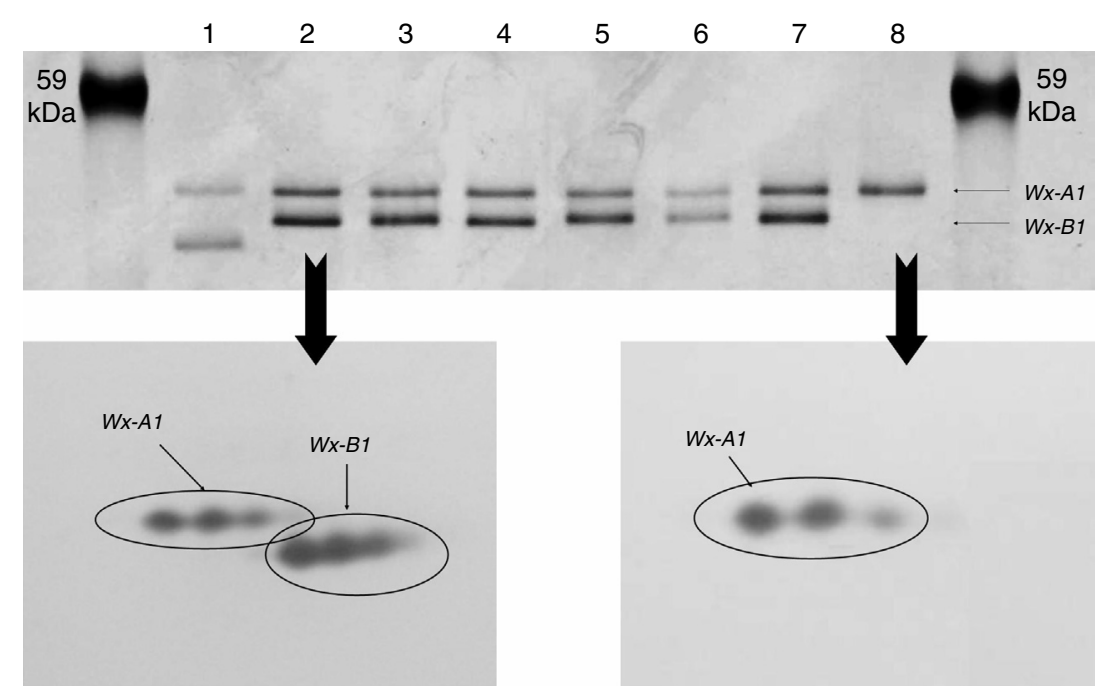

Fig. 1. Electrophoresis separation of waxy proteins in tetraploid wheats. One-dimensional SDS-PAGE (up) and two-dimensional IEF $\times$ SDS-PAGE (down). Lanes are as follows: 1, KU 4213D ( $W x-A 1 a$ and $W x-B 1 d) ; 2$ and 4, Emmer-71 (Wx-A1a and $W x-B 1 a) ; 3$ and 7, cv. Langdon $(W x-A 1 a$ and $W x-B 1 a) ; 5$, cv. Mexicali $\left(W x-A 1 a\right.$ and $\left.W x-B 1 c^{\prime}\right) ; 6$, Emmer-49 $(W x-A 1 a$ and $\left.W x-B 1 C^{\prime}\right) ; 8$, Emmer-52 (Wx-A1a and $\left.W x-B 1 b\right)$.

(emmer and spelt). This is in agreement with studies that suggest that the A genome of einkorn is substantially different from the A genome present in emmer and spelt (Dvorak et al., 1993).

Emmer did not show polymorphism for the $W x-A 1$ locus, whereas in spelt 36 , accessions that presented the $W x-A 1 b$ allele (null type) were detected. The $W x-A 1 a$ alleles detected in both species were similar to the allele detected in the durum and common wheat cultivars used as standards (Langdon and Mexicali, and Chinese Spring, respectively).

The variability for the $W x-B 1$ locus was higher in both polyploid species. However, most of the emmer accessions present the $W x-B 1 a$ allele, similar to the alleles found in cvs. Langdon and Chinese Spring. The other two alleles were very rare. Because SDSPAGE can occasionally generate overlapping bands that yield misleading results, the accessions that presented the null allele were analyzed by twodimensional electrophoresis (IEF $\times$ SDS-PAGE). The data revealed that the $W x-B 1$ gene is not expressed in this accession (Fig. 1).

The results were very similar for the $W x-D 1$ locus, with all accessions showing the $W x-D 1 a$ allele with exception of one accession that presented the $W x-D 1 b$ allele and another a novel allele named $W x-D 1 g$, which exhibited a slightly lower electrophoretic mobility than the $W x-D 1 a$ allele.

The mean expected heterocigosity $\left(H_{\mathrm{e}}\right)$ values were very low for all species (Table 1), representing approximately $13.4,5.5$ and $48.6 \%$ of the genetic diversity for einkorn, emmer and spelt, respectively, if the allelic variants of each locus were distributed randomly.
In conclusion, the current study has shown that Spanish hulled wheats exhibit significant waxy protein variation, with some novel alleles at risk of erosion by genetic drift. Consequently, the safeguarding of these and other hulled wheat accessions stored in germplasm banks is fundamental for the maintenance of genetic diversity. This diversity may be of use in breeding programmes focussed on starch quality, for both modern wheats and these ancient crops that are undergoing such a revival.

\section{Acknowledgements}

This research was supported by grant AGL2007-65685C02-02 from the Spanish Ministry of Science and Innovation and the European Regional Development Fund (FEDER) from the European Union. The first author thanks to the Spanish Ministry of Education and Science (FPU programme) for a predoctoral fellowship.

\section{References}

Ainsworth CC, Clark J and Balsdon J (1993) Expression, organization and structure of the genes encoding the waxy protein (granule-bound starch synthase) in wheat. Plant Molecular Biology 22: 67-82.

Alvarez JB, Moral A and Martín LM (2006) Polymorphism and genetic diversity for the seed storage proteins in Spanish cultivated einkorn wheat (Triticum monococcum L. ssp. monococcum). Genetic Resources and Crop Evolution 53: 1061-1067. 
Caballero L, Martín LM and Alvarez JB (2001) Allelic variation of the HMW glutenin subunits in Spain accessions of spelt wheat. Theoretical and Applied Genetics 103: $124-128$.

Caballero L, Martín LM and Alvarez JB (2004a) Genetic variability of the low-molecular-weight glutenin subunits in spelt wheat (Triticum aestivum ssp. spelta L. em Thell.). Theoretical and Applied Genetics 108: 914-919.

Caballero L, Martín LM and Alvarez JB (2004b) Variation and genetic diversity for gliadins in Spanish spelt wheat accessions. Genetic Resources and Crop Evolution 51: 679-686.

Caballero L, Bancel E, Debiton C and Branlard G (2008) Granule-bound starch synthase (GBSS) diversity of ancient wheat and related species. Plant Breeding 127: $548-553$.

Dvorak J, Terlizzi P, Zhang HB and Resta P (1993) The evolution of polyploidy wheats: identification of the A genome species. Genome 36: 21-31.

Echt CS and Schwartz D (1981) Evidence for the inclusion of controlling elements within structural gene at the waxy locus in maize. Genetics 99: 275-284.
Laemmli UK (1970) Cleavage of structural proteins during the assembly of the head of bacteriophage T4. Nature 227: 680-685.

Pflüger LA, Martín LM and Alvarez JB (2001) Variation in the HMW and LMW glutenin subunits from Spanish accessions of emmer wheat (Triticum turgidum ssp. dicoccum Schrank). Theoretical and Applied Genetics 102: $767-772$.

Rodríguez-Quijano M, Nieto-Taladriz MT and Carrillo JM (1998) Polymorphism of waxy proteins in Iberian hexaploid wheats. Plant Breeding 117: 341-344.

Yamamori M, Nakamura T, Endo R and Nagamine T (1994) Waxy protein deficiency and chromosomal location of coding genes in common wheat. Theoretical and Applied Genetics 89: 179-184.

Yamamori M, Nakamura $\mathrm{T}$ and Nagamine $\mathrm{T}$ (1995) Polymorphism of two waxy proteins in the emmer group of tetraploid wheat, Triticum dicoccoides, T. dicoccum, and T. durum. Plant Breeding 114: 215-218.

Zeng M, Morris CF and Batey Wrigley CW II (1997) Sources of variation for starch gelatinization, pasting, and gelation properties in wheat. Cereal Chemistry 74: 63-71. 